\title{
PFISR nightside observations of naturally enhanced ion acoustic lines, and their relation to boundary auroral features
}

\author{
R. G. Michell ${ }^{1,4}$, K. A. Lynch $^{1}$, C. J. Heinselman ${ }^{2}$, and H. C. Stenbaek-Nielsen ${ }^{3}$ \\ ${ }^{1}$ Dartmouth College, Department of Physics and Astronomy, Hanover, NH, USA \\ ${ }^{2}$ SRI, International, Menlo Park, CA, USA \\ ${ }^{3}$ University of Alaska, Fairbanks, Geophysical Institute, Fairbanks, AK, USA \\ ${ }^{4}$ currently at: Southwest Research Institute, San Antonio, TX, USA
}

Received: 6 December 2007 - Revised: 22 August 2008 - Accepted: 21 October 2008 - Published: 19 November 2008

\begin{abstract}
We present results from a coordinated camera and radar study of the auroral ionosphere conducted during March of 2006 from Poker Flat, Alaska. The campaign was conducted to coincide with engineering tests of the first quarter installation of the Poker Flat Incoherent Scatter Radar (PFISR). On 31 March 2006, a moderately intense auroral arc, $(\sim 10 \mathrm{kR}$ at $557.7 \mathrm{~nm})$, was located in the local magnetic zenith at Poker Flat. During this event the radar observed 7 distinct periods of abnormally large backscattered power from the F-region. These were only observed in the field-aligned radar beam, and radar spectra from these seven times show naturally enhanced ion-acoustic lines (NEIALs), the first observed with PFISR. These times corresponded to (a) when the polar cap boundary of the auroral oval passed through the magnetic zenith, and (b) when small-scale filamentary dark structures were visible in the magnetic zenith. The presence of both (a) and (b) was necessary for their occurrence. Soft electron precipitation occurs near the magnetic zenith during these same times. The electron density in the vicinity where NEIALs have been observed by previous studies is roughly between 5 and $30 \times 10^{10} \mathrm{~m}^{-3}$. Broadband extremely low frequency (BBELF) wave activity is observed in situ by satellites and sounding rockets to occur with similar morphology, during active auroral conditions, associated with the poleward edge of the aurora and soft electron precipitation. The observations presented here suggest further investigation of the idea that NEIALs and BBELF wave activity are differently-observed aspects of the same wave phenomenon. If a connection between NEIALs and BBELF can be established with more data, this could provide a link between in situ measurements of downward current regions (DCRs) and dynamic aurora, and ground-based observations of dark auroral structures and NEIALs. Identification of in situ processes, namely wave activity, in ground-based signa-
\end{abstract}

Correspondence to: R. G. Michell

(rmichell@swri.edu) tures could have many implications. One specific example of interest is identifying and following the temporal and spatial evolution of regions of potential ion outflow over large spatial and temporal scales using ground-based optical observations.

Keywords. Ionosphere (Plasma waves and instabilities; Wave-particle interactions) - Magnetospheric physics (Auroral phenomena)

\section{Introduction}

The ground-based camera and radar communities and the in situ satellite and sounding rocket communities observe the same auroral processes using very different methods. The motivation for this study is to interpret ground-based observations from imagers and radars in the context of recent observations made by sounding rockets and satellites. The recent NSF commissioning of PFISR, which is based on Advanced Modular Incoherent Scatter Radar (AMISR) technology, at Poker Flat Research Range (PFRR) (Kelly et al., 2006) allows a new high-resolution view of nightside auroral processes.

PFISR allows for observation of the nightside auroral oval using frequencies in the $450 \mathrm{MHz}$ range. In comparison, the location of the well-established European Incoherent Scatter (EISCAT) Svalbard Radar (ESR), which operates at $500 \mathrm{MHz}$ is optimized for dayside studies. The EISCAT mainland radars however are located under the nightside auroral oval (like PFISR), but operate at different frequencies (933 MHz and $224 \mathrm{MHz}$ ). It is well known that the auroral processes that occur on the dayside can be very different from those on the nightside, in fact, the auroral morphology is often more ordered on the nightside (Paschmann et al., 2003). Therefore identification of processes associated with specific auroral forms is likely to be more straightforward

Published by Copernicus Publications on behalf of the European Geosciences Union. 
on the nightside. PFISR provides an opportunity for making these types of nightside observations in the $450 \mathrm{MHz}$ range.

In this paper we present an event study from some of the very first available PFISR data. We show an example of the morphology and structure of naturally enhanced ion acoustic line (NEIAL) occurrence in nightside discrete aurora, and draw connections to well-established in situ observations. Specifically, the data suggest that nightside NEIALs are observed to contain matching morphology and overlapping parameters with broad-band extremely low-frequency (BBELF) waves that are seen in situ with satellites and rockets. These observations motivate the need for further investigation of this possible connection.

The outline of this paper is as follows. First, we review the in situ measurements which will provide context for our ground-based observations. A review of previous studies involving incoherent scatter radar observations of NEIALs is presented in the next section. Then we describe the methods used and present the observations from this camera and radar study. In the last sections, we discuss these observations in the context of the scientific background and conclude with a summary and the implications of this study.

\section{Scientific context}

\subsection{In situ}

We wish to consider radar observations of NEIALs in the context of in situ measurements of auroral processes. Based on the known NEIAL morphology (Rietveld et al., 1991; Collis et al., 1991; Rietveld et al., 1996; SedgemoreSchulthess et al., 1999; Ogawa et al., 2000; Grydeland et al., 2003, 2004; Blixt et al., 2005; Ogawa et al., 2006; Lunde et al., 2007), we are interested primarily in auroral processes associated with the polar cap boundary and Alfvénic regions, especially those associated with ion outflow. These are the nightside regions containing the same in situ processes as the dayside auroral regions shown to contain NEIALs. In situ measurements of upflowing ion beams have been shown to be associated with luminous auroral arcs (McFadden et al., 1998), but the dominant source of nightside ion outflow from the ionosphere to the magnetosphere has been shown to occur in the polar cap boundary and Alfvénic regions, in both nightside and cusp aurora (Bonnell et al., 1996; Lynch et al., 1996; Kintner et al., 1996; Norqvist et al., 1998; André et al., 1998; Knudsen and Wahlund, 1998; Lynch et al., 2002; Strangeway et al., 2005; Zheng et al., 2005). The polar cap boundary and Alfvénic regions are characterized by their soft electron precipitation, with energies of less than $1 \mathrm{keV}$, typically a few hundred eV (Louarn et al., 1994; Chaston et al., 2003, 1999; Arnoldy et al., 1999; Lynch et al., 2007). A commonly observed feature of these polar cap boundary and Alfvénic regions is broad-band extremely low frequency (BBELF) wave activity as described with case and statistical studies by Lynch et al. (2002), and summarized in Sect. 4.3.1.3 of Paschmann et al. (2003). BBELF waves have been found to be associated with perpendicular ion heating, ion upflow and outflow near the polar cap boundary (Bonnell et al., 1996; Kintner et al., 1996; Lynch et al., 1996, 2002; Knudsen and Wahlund, 1998; Wahlund et al., 1998), as well as with the upgoing soft electron beams of downward current regions (DCRs) (Paschmann et al., 2003). DCRs are also associated with ion upflow (Lynch et al., 2002).

Figure 1 illustrates typical examples of these in situ observations as seen by the Fast Auroral SnapshoT (FAST) spacecraft (Carlson et al., 1998; Paschmann et al., 2003), for nightside (left) and dayside (right) cases. The panels show, (a) the east-west magnetometer deflection, (b) and (c) the upgoing and downgoing electron energy spectrograms, (d) the electron pitch angle spectrograms, (e) and (f) the ion energy and pitch angle spectrograms, (g) and (h) the ELF wave power plotted on linear and logarithmic frequency axes. Downward-current regions are characterized by a positive slope on the east-west magnetometer deflection, and upwardcurrent regions (UCR) by a negative slope. It can be seen from the nightside example (Orbit 1626) that there is one large well-defined DCR in the center, which contains intense fluxes of up-going electrons (19:07-19:09 UT). The dayside example (Orbit 1752) shows DCRs which are more structured and contain several DCRs occurring alongside UCRs; these regions are smaller and interspersed with one another. DCRs are associated with large fluxes of up-going soft electrons, perpendicularly heated ions, and BBELF wave activity in the few $\mathrm{kHz}$ range. The polar cap boundary and Alfvénic regions, not shown here, contain a mixture of upward and downward current, varying in space and or in time. An example may be seen in Fig. 4.2 of Paschmann et al. (2003).

BBELF in PCB and Alfvénic regions is associated with soft electron precipitation (low energy downgoing electrons). The BBELF is seen to occur in the frequency range of 0.1 to $10 \mathrm{kHz}$, encompassing the band (4 to $8 \mathrm{kHz})$ where the ionacoustic peaks occur in the radar data. Previous studies of BBELF have invoked the current-driven instability (Kindel and Kennel, 1971) as its generation mechanism (Kintner et al., 1996; Bonnell et al., 1996). The current-driven instability however requires large current densities, which have not been accurately measured. However, magnetic measurements from the Ørsted satellite have indicated the presence of finely structured field-aligned currents (Neubert and Christiansen, 2003), which implies the presence of very large local current densities even when the large-scale average current density is low. Other theories for BBELF invoke the tearing mode instability to generate the electric field activity (Seyler and $\mathrm{Wu}, 2001$ ). More recent studies have shown that Alfvén waves can become turbulent in ionospheric density cavities, producing a broad-band electric field signature very similar to that of BBELF (Chaston et al., 2006). The Alfvén resonator model of Streltsov and Lotko (2005), shows promise for producing Doppler broadened spatial structures 
consistent with BBELF signatures measured in situ. Any realistic model of BBELF needs to involve both wave activity at ion frequencies and Doppler broadening, both from the motion of the observational platform and from plasma flows.

\subsection{Ground based observations}

Incoherent scatter radar (ISR) can provide altitude profiles of ionospheric electron density $\left(N_{e}\right)$, electron temperature $\left(T_{e}\right)$, ion temperature $\left(T_{i}\right)$, and line-of sight ion flow velocity $\left(V_{i}\right)$. The procedure for obtaining these quantities involves fitting theoretical spectra to the radar spectra. The main assumption of this fitting is that the plasma is nearly Maxwellian (Rosenbluth and Rostoker, 1962). Typical ISR spectra from a thermal plasma consist of a double humped peak centered near the transmitted frequency, with the two humps offset by the ion-acoustic frequency (near $5 \mathrm{kHz}$ for PFISR). The two humps are caused by thermally excited ion-acoustic waves traveling toward and away from the radar. Significant departures from the thermal background spectra were first observed by Foster et al. (1988), who found the spectra to contain significantly enhanced (several orders of magnitude above thermal levels) ion-acoustic lines that were extended in altitude and lasted for short (tens of seconds) time intervals. Enhanced returns that come from a very limited altitude range are assumed to be scattering from a hard target, such as a satellite, but when these large returns are extended in altitude along the geomagnetic field, they are assumed to be of geophysical origin. The frequency offset (Doppler shift) of the enhanced returns can also indicate whether they are from NEIALs or satellites. NEIALs are of great interest as they are an indication of processes that are not fully understood, but empirically appear to be related to ion outflow (Ogawa et al., 2000; Forme and Fontaine, 1999).

Previous studies of NEIALs have found that certain aspects of auroral context are shared by the different NEIAL events. One of the first links to auroral context was the observation that NEIALs occurred during red aurora (Collis et al., 1991; Rietveld et al., 1991), indicative of soft electron precipitation. The large statistical study of NEIALs by Rietveld et al. (1996) does not significantly discuss the auroral structures associated with them, and therefore invites further investigation of NEIALs and associated auroral structure. Sedgemore-Schulthess et al. (1999), using the first highresolution narrow-angle $(\sim 20 \times \sim 30 \mathrm{~km}$ FOV at $105 \mathrm{~km}$ altitude) auroral television images with common-volume radar observations of NEIALs reported their occurrence near the cusp on the equatorward edge of a red auroral arc. They also found them to be associated with "coronal forms", which refers to tall auroral rays near the magnetic zenith, and small patches of luminosity in the magnetic zenith. Rietveld et al. (1996) first noted that ISR data are usually integrated in 10$\mathrm{s}$ intervals, and that auroral forms can vary on much faster timescales (second to sub-second), therefore the radar could be averaging in space, time or both. Sedgemore-Schulthess et al. (1999) also concluded that the simultaneously observed up- and down-shifted enhancements of the NEIALs could be the result of averaging by the radar and that they may not actually occur at the exact same time. Using interferometric methods and high time resolution, Grydeland et al. $(2003,2004)$ showed that the size of the structures producing the NEIALs were on the order of a few hundred meters in the direction perpendicular to the geomagnetic field at $500 \mathrm{~km}$ altitude, indicating that the actual enhancement within these structures when not averaged over the entire radar beam must be 4 to 5 orders of magnitude larger than the thermal level. Grydeland et al. (2003, 2004) also analyzed the raw radar data with 0.2 -s integration intervals, which revealed that on that timescale both the up and down shifted NEIALs sometimes occurred at the same time in the same location. Thus concluding that the simultaneously up- and down-shifted NEIALs are not a result of spatial or temporal averaging by the radar, down to the $200 \mathrm{~ms}$ integration times used.

Blixt et al. (2005) collected all the data sets that included both NEIALs and common-volume high-resolution narrow angle optical images of the aurora. There were only 4 such cases found, and all 4 of these were from dayside auroral features. Using these data, they were able to conclude that very dynamic rayed aurora were present for all the observations of NEIALs. This type of aurora can be associated with Alfvénic acceleration of electrons, which produces large numbers of low energy (sub-keV) precipitating electrons (Hallinan et al., 2001; Ivchenko et al., 2005). This is also indicated in the camera data by the large altitude extent of the auroral rays (Blixt et al., 2005). The auroral signatures they observed associated with the NEIALs also contained "flaming" and "pumping" aurora.

Three main theories for NEIAL generation have been developed. Two are based on streaming instabilities, with strong relative drifts between species, either ion-ion or ionelectron. One is based on the decay of Langmuir waves into ion-acoustic waves and secondary Langmuir waves (Groves, 1991; Forme, 1993). Only the ion-electron streaming (current driven) instability requires that the up- and down-shifted shoulders become enhanced individually. Recent observations support the Langmuir wave decay theory, as Grydeland et al. $(2003,2004)$ showed that both the up and downshifted NEIALs were enhanced simultaneously (within the $200 \mathrm{~ms}$ integration time used), and within a small region of space (few hundred meters perpendicular to B). Strømme et al. (2005) reported observing NEIALs in conjunction with enhanced plasma lines. The simultaneous observations of NEIALs with enhanced plasma lines provide strong evidence for the Langmuir decay theory. All these published theories assume that particle dynamics are the energy source for the enhanced wave activity. It is certainly possible that the alternative is true, that the wave enhancements are caused by turbulent evolution and dynamics of externally driven Alfvén wave activity (Chaston et al., 2003, 2006; Streltsov and 

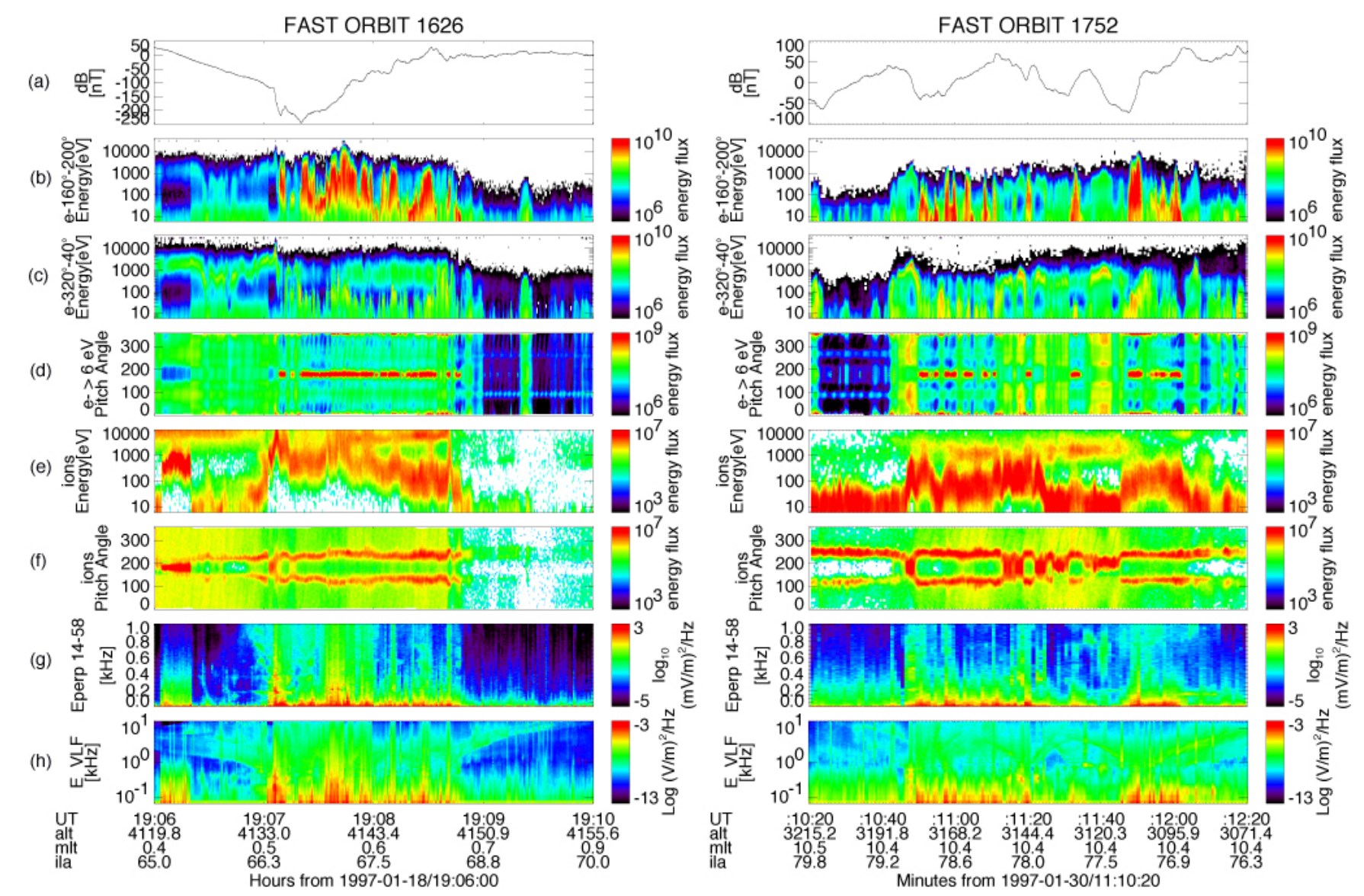

Fig. 1. Two excerpts from FAST auroral zone crossings. The left column spans $4 \mathrm{~min}$ and is from a nightside crossing, while the right column spans $2 \mathrm{~min}$ and is from a dayside crossing. From top to bottom, the panels show: (a) the east-west magnetic deflections, (b) and (c) the upgoing and downgoing electron spectrograms, (d) the electron pitch angle spectrograms, (e) and (f) the ion energy and pitch angle specrograms, (g) and (h) the ELF wave power plotted on linear and logarithmic frequecy axes. Figures provided by K.-J. Hwang.

Lotko, 2005; Wygant et al., 2000) combined with Doppler broadening, and that this is the source of the energy driving the soft electron precipitation. This picture is worth investigating for explaining the generation of both NEIALs and BBELF.

The connection between increased ion outflows and NEIALs has been established experimentally by Ogawa et al. (2000) and by Forme and Fontaine (1999). They find that the occurrence of NEIALs is associated with enhancements of electron temperature and electron density, indicating that soft precipitation processes are important. Forme (1999) developed a method to estimate the plasma parameters inside the turbulent regions associated with the NEIALs where the standard analysis procedure fails. They find using their method that the electron temperature in NEIAL regions with soft electron precipitation can be heated up to $11000 \mathrm{~K}$, and that ion outflow velocities can be as high as $1300 \mathrm{~m} / \mathrm{s}$ at $800 \mathrm{~km}$ altitude (assuming $\mathrm{O}^{+}$ions). Previous studies (St.-Maurice et al., 1996, 1999) and more recent modeling work (Lynch et al., 2007) show that soft electron precipitation causes an increase in $T_{e}$ and can lead to significant ion upflow.

\section{Method}

The PFISR engineering test phase in the winter of 2006 produced the opportunity to compare some of the first observations from PFISR with high resolution imaging of the common volume aurora. PFISR was operating with 32 panels during this time, one fourth of its final capacity of 128 panels. Based on AMISR technology, PFISR is composed of individual panels, each panel containing 32 crossed dipole Antenna Element Units (AEU). High-resolution television observations of the aurora were made during the two moon-down periods of February and March of 2006. Three separate cameras were used: an all-sky, a narrow field $\left(\mathrm{FOV} \sim 12^{\circ} \times 16^{\circ}\right)$, and a medium field (Xybion 750 with FOV $40^{\circ} \times 40^{\circ}$ ). All three cameras are image intensified CCD cameras with the capability of imaging the aurora at 30 frames per second. 


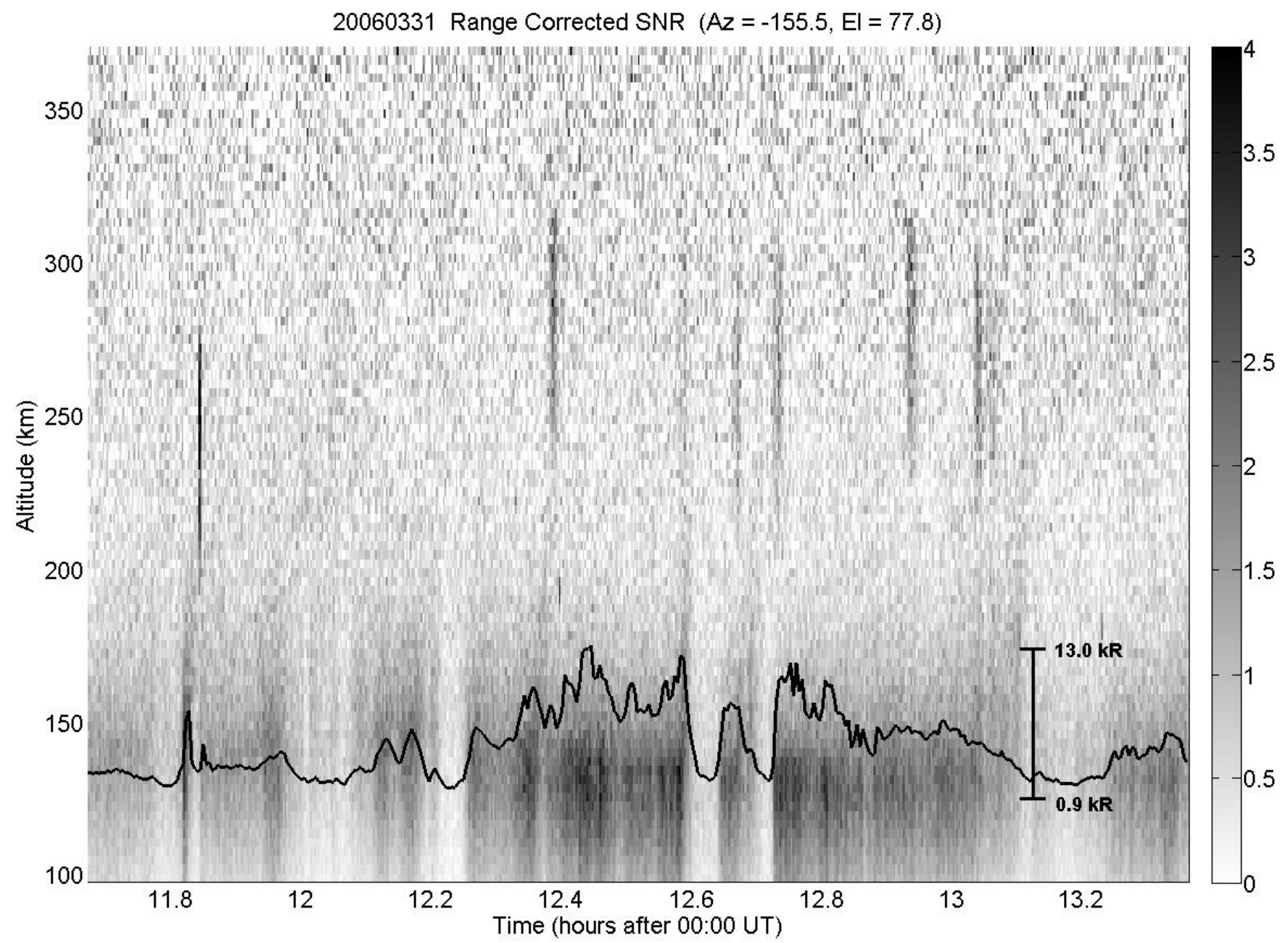

Fig. 2. The range-corrected SNR for 31 March 2006, showing the enhanced backscattered power from the F-region at the 7 times of the NEIAL, and the enhanced E-region from the auroral electron precipitation. The line plot shows the intensity of light from the MSP as a function of time averaged over the region of the radar beam. The intensity varies from 0.9 to $13 \mathrm{kR}$.

The narrow field and medium field cameras were positioned looking up the geomagnetic field, and the images from all 3 cameras were recorded at 30 frames per second. The narrow field and medium field cameras were filtered to cut the $557.7 \mathrm{~nm}$ emissions. The all-sky camera was unfiltered. The all-sky and narrow field are both owned by the Geophysical Institute at the University of Alaska, Fairbanks. In addition to the cameras, a meridian scanning photometer (MSP) was operating at Poker Flat. The MSP scans along the magnetic meridian and takes intensity readings at 4 wavelengths $(557.7 \mathrm{~nm}, 630.0 \mathrm{~nm}, 427.8 \mathrm{~nm}$, and $486.1 \mathrm{~nm})$ in one degree elevation steps. The time resolution of the MSP is one complete scan approximately every $17 \mathrm{~s}$.

The auroral activity, typical of solar minimum conditions, was generally very quiet, with a few nights of moderate auroral activity. On 31 March 2006, there was a moderately intense auroral arc, $(\sim 10 \mathrm{kR}$ at $557.7 \mathrm{~nm})$, located in the lo- cal magnetic zenith. During this night PFISR observed 7 distinct times of abnormally large backscattered power from the F-region in the field-aligned radar beam $\left(-155.5^{\circ} \mathrm{Az}\right.$., $77.8^{\circ}$ El.), (shown in the next section). There was not yet any calibration for PFISR, so it is not possible to compute the absolute electron density.

\section{Observations}

Figures 2 and 3 show overviews of the radar data and the auroral intensity for this event. The radar SNR for 31 March 2006 is plotted in Fig. 2 as a function of altitude and time and is integrated in $10 \mathrm{~s}$ windows. This power is corrected for the inverse square decrease in power as a function of range, and background-subtracted so that it will be proportional to the electron density. There are 7 times when the F-region can 




Fig. 3. The MSP data, summed over three wavelengths $(557.7 \mathrm{~nm}, 630.0 \mathrm{~nm}, 427.8 \mathrm{~nm})$ and plotted as an image of intensity versus elevation angle versus time. North is at an elevation of $0^{\circ}$, and the magnetic zenith is at $103^{\circ}$, indicated by the horizontal line. The seven vertical lines indicate the times of the seven NEIALs from Fig. 2. NEIALs are seen when the poleward edge of the auroral activity intersects the zenith-looking radar beam.

be seen to contain enhancements well above the background levels. These enhancements are indicative of NEIALs because they are extended in altitude and the spectra at those times show significant enhancements above thermal levels at the ion-acoustic shoulders. These enhancements however, appear to differ from many of the previous NEIAL observations. Here the level of enhancement is approximately between a factor of 3 and 5, as opposed to orders of magnitude. The spectra also show a lot of power spread between the peaks, see Fig. 4, and in some cases there is even a discernible central peak (not shown here). These observations are consistent with NEIALs, but they appear to differ from previous observations, perhaps indicating a different generation mechanism.

These data were taken with PFISR running at $449.3 \mathrm{MHz}$, using $500 \mu$ s long, uncoded pulses, which leads to $\sim 75 \mathrm{~km}$ of range smearing. This altitude range is comparable to the altitude extent over which these enhancements appear. The spectra shown in Fig. 4, mentioned above, show that the returned power is spread throughout and between both ionacoustic shoulders, indicating that these enhancements are not from hard target scattering. Further evidence that these enhancements are of geophysical origin is that they only appear in the field-aligned radar beam $\left(204.5^{\circ} \mathrm{Az}\right.$., $77.8^{\circ} \mathrm{El}$.), and no similar enhancements were observed in any of the other 3 beams that were looking oblique to the magnetic field $\left[\left(-35.0^{\circ} \mathrm{Az} ., 68.9^{\circ} \mathrm{El}.\right) ;\left(82.9^{\circ} \mathrm{Az} ., 70.5^{\circ} \mathrm{El}.\right) ;\left(0.0^{\circ} \mathrm{Az}\right.\right.$. $90.0^{\circ} \mathrm{El}$.)], despite very similar looking E-region enhancements from auroral particle precipitation.

Figure 3 shows a survey of the optical aurora using the MSP data, summed over the three channels $(557.7 \mathrm{~nm}$, $630.0 \mathrm{~nm}$, and $427.8 \mathrm{~nm}$ ). There were no significant 
emissions in the $486.1 \mathrm{~nm}$ channel. This figure shows the intensity of the aurora along the magnetic meridian as a function of time. North is at $0^{\circ}$ elevation and the magnetic zenith is at $103^{\circ}$, which is indicated by the horizontal line. The time resolution of the MSP data is about $17 \mathrm{~s}$, which is comparable to the 10-s resolution of the radar data (all the NEIALs occur over 2 or more of the radar integrations). The 7 vertical lines on Fig. 3 represent the times of the 7 NEIALs visible in Fig. 2. The NEIALs are present when the poleward edge of the aurora crosses the radar beam at the magnetic zenith.

The spectrum of the second NEIAL is shown in Fig. 4. The power is averaged over the altitude range that the NEIAL occurs in, and is plotted both as (a) power-frequency-time, and (b) as a line plot which is averaged over the time interval that the NEIAL occurs. The dotted line on the line plot shows the background power level taken from a similar time and altitude range within a minute of the time when the NEIAL occurred. These data were also integrated into 10-s windows.

Figure 5 shows the narrow field camera images during the 7 NEIAL events, showing the small-scale ( $\sim 1 \mathrm{~km}$ or less) structure visible in the magnetic zenith. NEIAL \#1 is associated with a small, rayed, fast-moving dynamic auroral arc with a velocity of a few $\mathrm{km} / \mathrm{s}$ perpendicular to $\mathrm{B}$, and motions of structures along the arc with speeds of $\sim 10 \mathrm{~km} / \mathrm{s}$. The velocities were derived assuming an altitude of $100 \mathrm{~km}$. The strong returns associated with NEIAL \#1 were found to occur in the dark region adjacent to the small, rayed auroral arc. NEIALs \#2 through \#7 are all associated with thin, filamentary dark auroral structures on the order of $1 \mathrm{~km}$ thick. The narrow field camera images in Fig. 5 are from representative times during the NEIAL events. There were filamentary dark structures present during all 7 NEIALs.

NEIALs \#2, \#3, and \#5 are associated with both light and dark filamentary structures, with scale sizes smaller than the radar beam. Therefore from these alone, it cannot be determined if the NEIALs are associated with the light or dark filamentary structures. Examining the remaining NEIALs, there are 3 which are associated with only dark filamentary structures, NEIAL \#4, \#6, and \#7. This is possible because there was an unstructured background of luminous aurora, and these filamentary black features moved through this unstructured background, very similar to black aurora (as is often seen in diffuse aurora) (Trondsen and Cogger, 1997). The remaining NEIAL, NEIAL \#1, appears to be associated with only a luminous auroral structure, when examined using the integrated radar data. This NEIAL, however, had the strongest signal, which allowed for some analysis of the raw data to be done. By examining the raw data (not shown here), the exact time of the NEIAL returns could be localized with less than $1 \mathrm{~s}$ time resolution. This high resolution raw data revealed that these NEIAL returns were coming from the dark region next to the arc, similar to the NEIAL event reported in Michell et al. (2008). The raw data were examined for the other 6 NEIAL events, but the unintegrated signal was not strong enough to be able to make a meaningful compari-

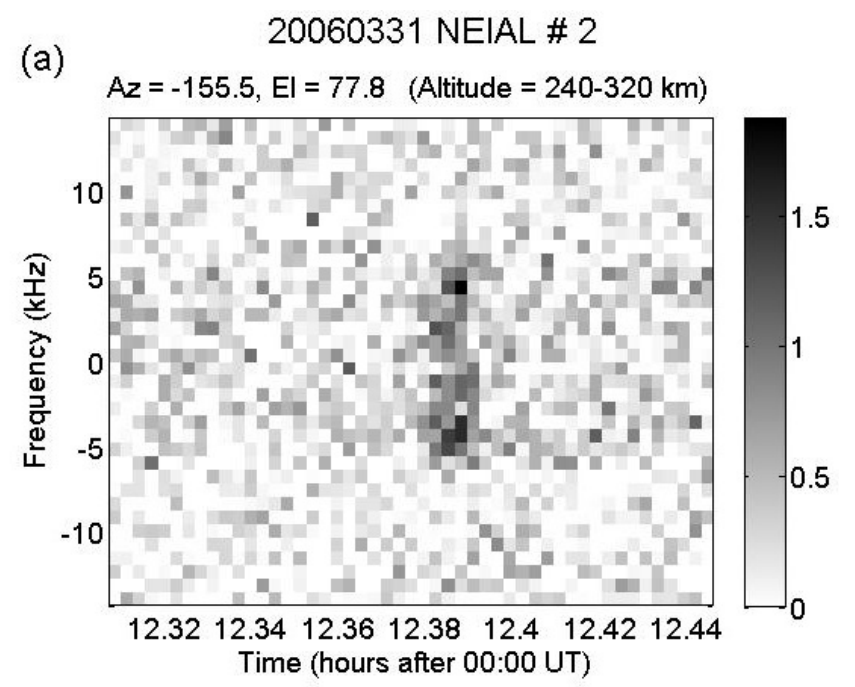

(b)

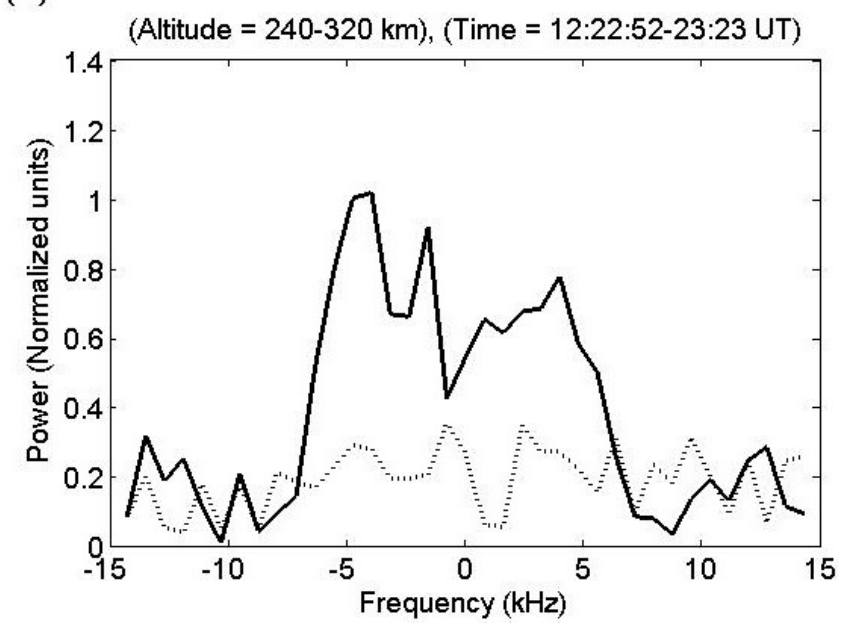

Fig. 4. The spectra of NEIAL \#2. (a) Power versus frequency and time, averaged over the altitude range in which the NEIAL occurs. (b) Line plot showing the power versus frequency averaged over the altitude and time of the NEIAL. The dotted line on (b) is the background level taken from a similar time interval within a minute of the NEIAL event.

son to the high resolution optical data. The common auroral feature between all 7 of the NEIALs is the presence of filamentary dark auroral structures, even though most are also associated with filamentary luminous auroral features.

The dark structures all showed apparent motions, relative to the bright auroral features present. All of the auroral structures associated with the NEIALs, with the exception of \#1, are embedded within the poleward edge of a large-scale auroral arc structure as can be seen in Fig. 7.

Figure 2 showed that the E-region enhancement sometimes tends to extend up to higher altitudes near the times when the NEIALs are observed. This indicates that the energy spectrum of the precipitating electrons at those times 

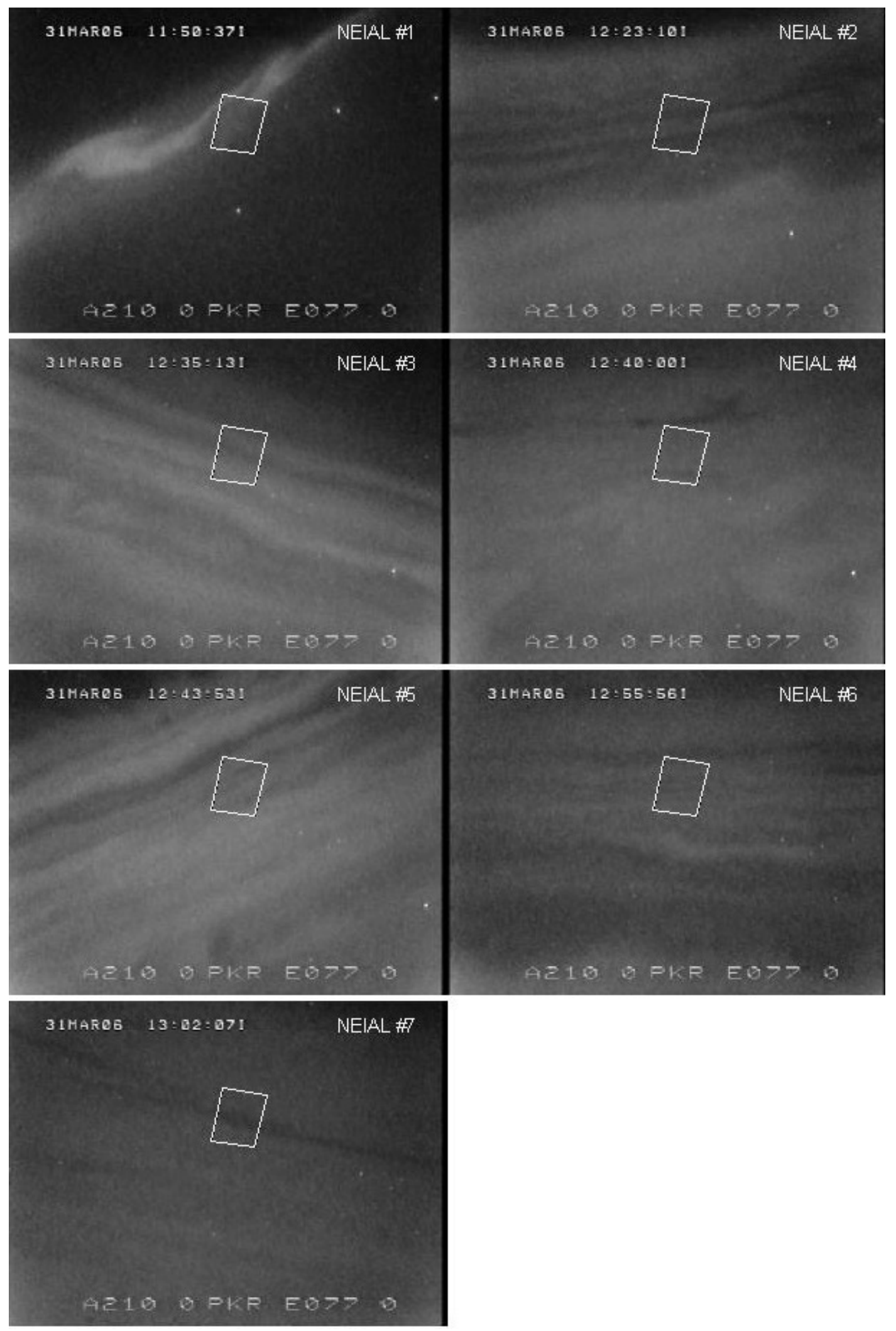

Fig. 5. The narrow field camera images from the 7 NEIALs, showing the small-scale structure visible in and around the magnetic zenith. The white box shows the size and location of the PFISR beam mapped to $100 \mathrm{~km}$ altitude. 


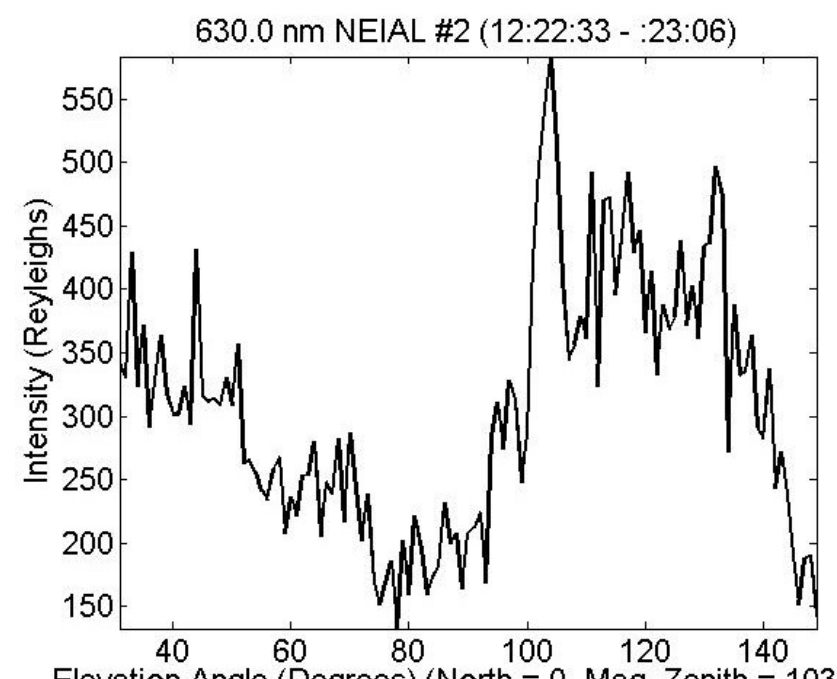

Elevation Angle (Degrees) (North = 0, Mag. Zenith =103)

Fig. 6. The mean of three consecutive scans of the $630.0 \mathrm{~nm}$ channel of the Poker Flat MSP along the magnetic north-south direction at around 12:23 UT, which corresponds to the time of NEIAL \#2. The magnetic zenith is at $103^{\circ}$ and north is at $0^{\circ}$.

contains a larger soft (sub keV) electron component. These soft electrons deposit their energy and cause ionization over a larger altitude range, extending to higher altitudes. Further evidence of this soft electron precipitation comes from the MSP data. Soft electron precipitation produces more $630.0 \mathrm{~nm}$ emissions than the harder $(>1 \mathrm{keV})$ "inverted-V" electrons. The harder electrons deposit their energy at lower altitudes where the $630.0 \mathrm{~nm}$ emissions are collisionally quenched and therefore $557.7 \mathrm{~nm}$ and $427.8 \mathrm{~nm}$ are the dominant emissions there.

The enhanced E-region near the times of the NEIALs could be associated with increased electron density or increased ion temperatures, or both. The MSP observes enhanced $630.0 \mathrm{~nm}$ emissions in the vicinity of the magnetic zenith at the times when the NEIALs occur. This can be seen in Fig. 6, which shows an example of the MSP data for the time of the second NEIAL (at about 12:23 UT). The MSP data plotted in Fig. 6 is an average of three consecutive scans along the magnetic north-south direction for the $630.0 \mathrm{~nm}$ channel. This is a time average of the MSP data over the length of time for which NEIAL \#2 existed. North is at $0^{\circ}$, and the magnetic zenith is at $103^{\circ}$. The magnetic zenith is just poleward of the most intense $630.0 \mathrm{~nm}$ peak. The times of the other six NEIALs (not shown here) show similar structure in the $630.0 \mathrm{~nm}$ channel, where the most intense emissions are in or just equatorward of the magnetic zenith. The enhanced $630.0 \mathrm{~nm}$ emissions near the zenith indicate that the aurora in that region was associated with the largest flux of soft electron precipitation.

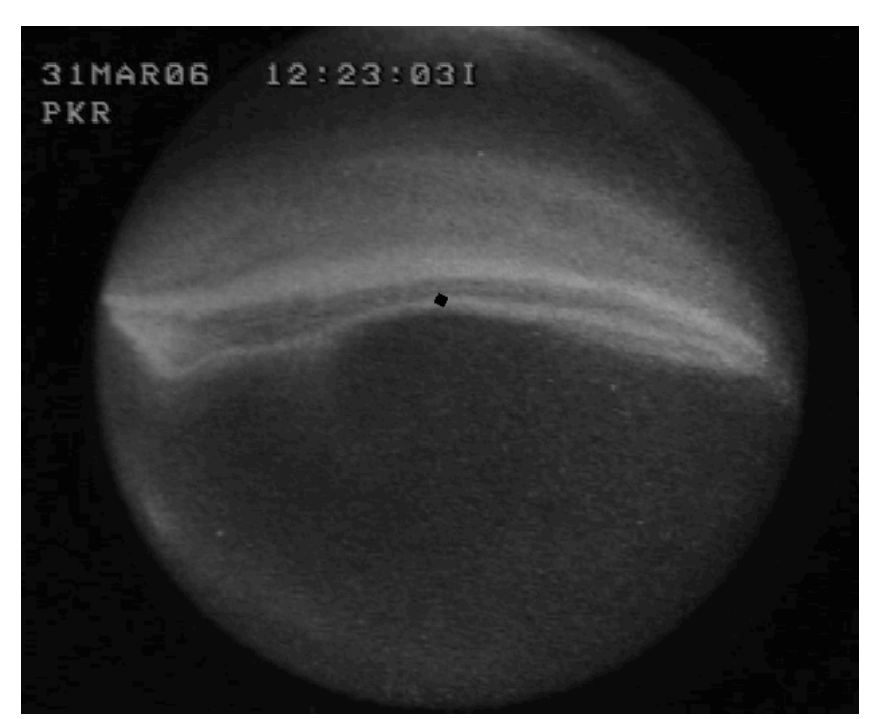

Fig. 7. An all-sky camera image showing the auroral arc location relative to the field-aligned radar beam location at $100 \mathrm{~km}$ altitude. North is on the bottom and east is to the right. This image corresponds to the time of NEIAL \#2.

Figure 3 shows that the NEIAL events are occurring at or very near the poleward edge of the aurora. The MSP data from the magnetic zenith in the $557.7 \mathrm{~nm}$ and $427.8 \mathrm{~nm}$ channels of the MSP were compared to the E-region relative electron density from Fig. 2. The intensity of the aurora in both channels was found to match the relative electron density very closely (i.e., the brighter the aurora, the higher the electron density). The line plot on Fig. 2 is the $557.7 \mathrm{~nm}$ MSP data from the magnetic zenith, integrated over the size of the radar beam at $100 \mathrm{~km}$ altitude. This indicates that the enhanced E-region electron density is caused by auroral electron precipitation, as the intensity of the aurora closely follows the electron density. The all-sky camera images also confirm that the times when the NEIALs occur are when the poleward edge of the auroral arc passes through the magnetic zenith. Figure 7 shows an all sky camera image from the time of NEIAL \#2, where the small black box in the center marks the location of the PFISR beam at $100 \mathrm{~km}$ altitude. In this figure north is at the bottom and east is to the right. The all-sky camera movie showed that the auroral arc moved slowly north and south several times throughout these two hours, and each time the poleward edge crossed the radar beam, NEIALs were observed with PFISR. It did not appear to matter whether the aurora was moving north or south when it crossed the radar beam.

There are two important points to note about the auroral context in which these NEIAL events occurred. The occurrence is in association with the poleward edge of the auroral arc, consistent with regions of soft electron precipitation. Dynamic and filamentary dark auroral structures are present in the magnetic zenith when the NEIALs appear. 


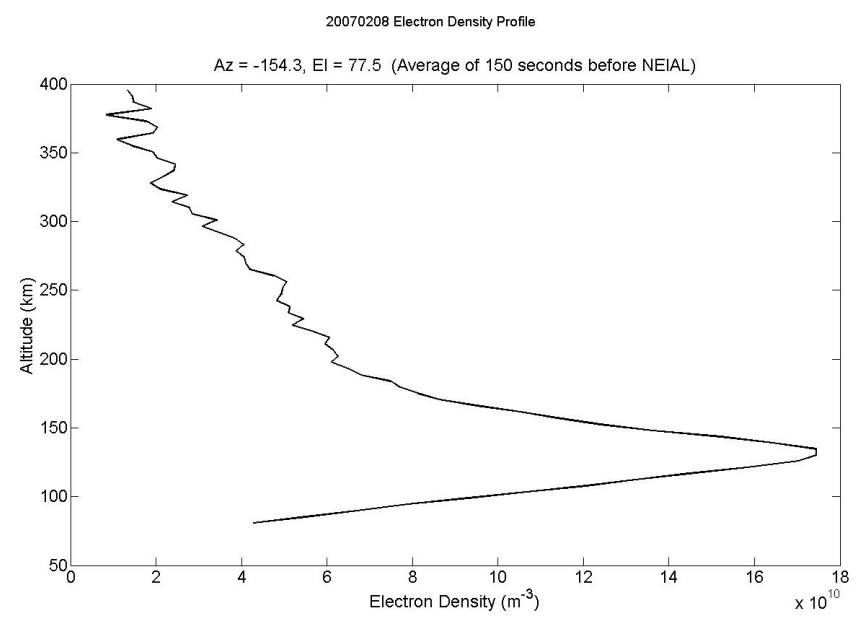

Fig. 8. The electron density (in $\mathrm{m}^{-3}$ ) versus altitude for the 150 second period before the NEIAL event reported in Michell et al. (2008), showing that the winter, nightside ionosphere typically contains an enhanced E-region, but no significant F-region.

\section{Discussion}

In this section, the nightside NEIAL observations are first compared to previous dayside NEIAL observations. The auroral morphology and context of these nightside observations is then examined. A summary of the know characteristics of BBELF is presented in the next sub-section, and finally the implications for the theories of NEIAL generation are examined.

\subsection{Comparison to previous NEIAL observations}

The nightside NEIALs presented here are observed at a lower altitude (from 200 to $325 \mathrm{~km}$ ) than the altitudes of 500 to $800 \mathrm{~km}$ for dayside NEIAL observations (Grydeland et al., 2003, 2004; Strømme et al., 2005; Ogawa et al., 2000; Forme and Fontaine, 1999). It is reasonable that the processes producing the NEIALs contain plasma density dependences, resulting in a higher altitude of occurrence on the dayside. Rietveld et al. (1991) reporting on morning-side NEIALs, find them occurring at lower altitudes, down to $140 \mathrm{~km}$. Rietveld et al. (1996) reviewed a large number of NEIAL observations, with both dayside and nightside coverage, and found that NEIALs occurred between the altitudes of 150 and $600 \mathrm{~km}$, with the majority above $250 \mathrm{~km}$. The densities and altitudes associated with the previous NEIAL studies are summarized in Table 1. The data from Michell et al. (2008) are also included. The Sondrestrom radar at $1290 \mathrm{MHz}$ is not listed, as NEIALs have never been observed with this radar. The electron densities associated with these previous NEIAL occurrences are all near $10 \times 10^{10} \mathrm{~m}^{-3}$. The total range of electron densities measured is typically between 1 and $100 \times 10^{10} \mathrm{~m}^{-3}$. This suggests that the altitude differ-

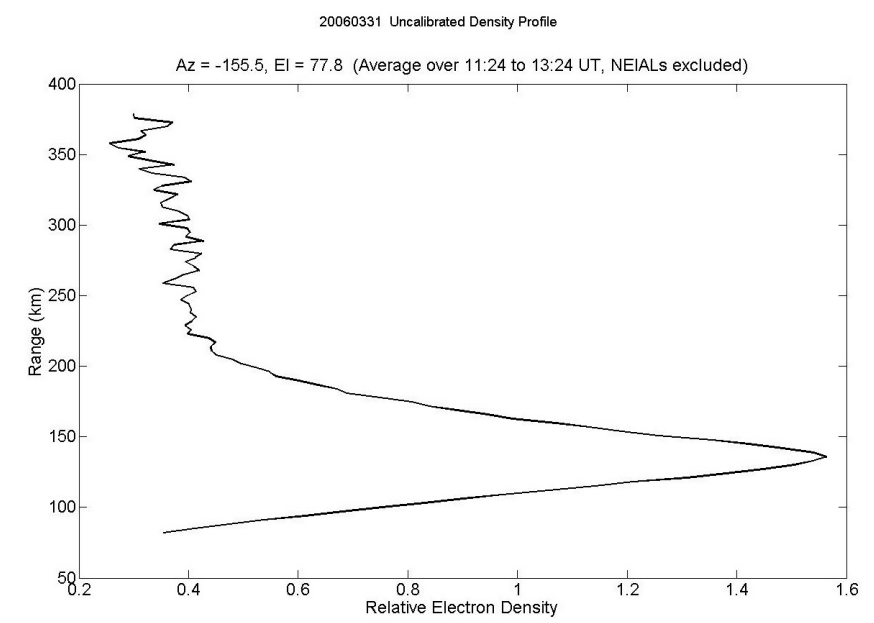

Fig. 9. The uncalibrated, relative electron density versus altitude for the $2 \mathrm{~h}$ period during the NEIAL events of 31 March 2006. This is an average over the period from 11:24 UT to 13:24 UT with the NEIALs excluded.

ences associated with the different studies are caused by a density dependence. More case studies are needed, to examine both the auroral context and the other parameters derivable from the radar data, to give more insight into NEIAL generation mechanisms.

This density dependence could be used to constrain the theories of NEIAL generation. Given the available data, however, it is difficult to tell whether NEIALs are associated with localized density depletions or enhancements, as they often are associated with structures that are smaller than the radar beam size. For example, Fig. 8 shows the electron density versus altitude for the nightside, winter NEIAL event of Michell et al. (2008). The profile plotted here is an average over $150 \mathrm{~s}$ taken immediately before that NEIAL event ( 8 February 2007), as this is the only PFISR event available so far where absolute electron density can be obtained. Figure 8 shows the enhanced E-region due to diffuse auroral precipitation, and that there is no F-region peak. The density continuously decreases with altitude above the E-region peak. The NEIAL event reported here was seen with a similarly shaped electron density profile, shown in Fig. 9. For this event, only the relative electron density is known. A density estimate was made by comparing to recent PFISR data of very similar auroral activity with calibrated electron density, and it was found that the proportionality constant is approximately $1.6 \times 10^{11} \mathrm{~m}^{-3}$. This results in a density range of 5 to $9 \times 10^{10} \mathrm{~m}^{-3}$ for the altitude range of 200 to $300 \mathrm{~km}$, which is consistent with the densities associated with the previous NEIAL observations.

The dayside studies find NEIALs to occur at higher altitudes and in those cases, the NEIALs only occur on the topside of the F-region, where the density is within this same range. 
Table 1. Summary of the altitudes and densities associated with NEIAL studies. The overall range of densities typically measured is 1 to $100 \times 10^{4} \mathrm{~cm}^{-3}$

\begin{tabular}{|c|c|c|c|c|c|}
\hline Paper & Freq. (MHz) & MLT & Alt. (km) & $\log (\mathrm{Ne})\left(\mathrm{m}^{-3}\right)$ & $\mathrm{Ne}\left(10^{4} \mathrm{~cm}^{-3}\right)$ \\
\hline Rietveld et al. (1991) & 933 & $07: 15-07: 45$ & $150-500$ & $11.0-11.3$ & $10-20$ \\
\hline Forme and Fontaine (1999) & 224 & $15: 30-16: 00$ & $500-1000$ & $10.9-11.5$ & $8-31$ \\
\hline Sedgemore-Schulthess et al. (1999) & 500 & 09:45-10:00 & $300-450$ & $10.8-11.1$ & $6-12$ \\
\hline Ogawa et al. (2000) & 500 & $10: 15,13: 15$ & $600-700$ & $11.0-11.3$ & $10-20$ \\
\hline Grydeland et al. (2004) & 500 & $08: 30$ & $400-700$ & not listed & NA \\
\hline Michell et al. (2008) & 449 & $22: 10$ & $200-350$ & $10.7-11.0$ & $5-10$ \\
\hline
\end{tabular}

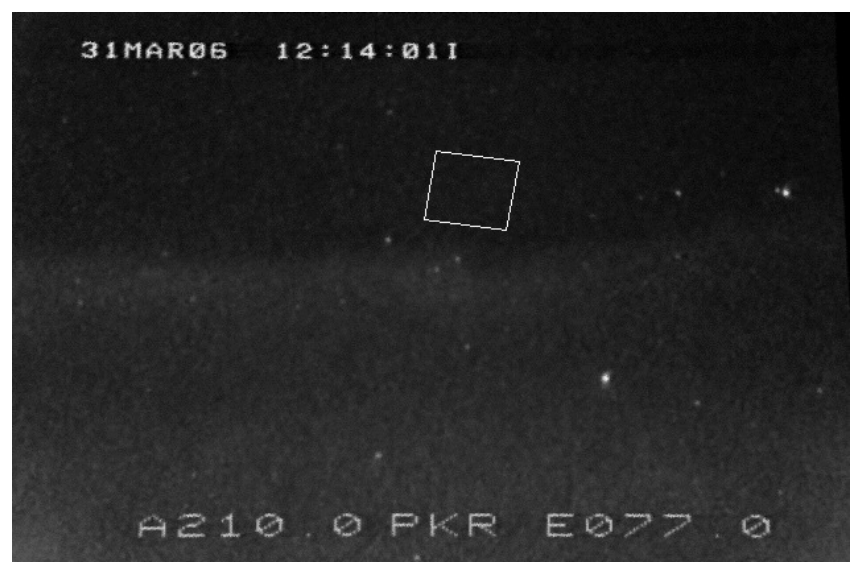

Fig. 10. An example narrow field camera image from 31 March 2006, showing the lack of filamentary dark auroral structures present in the magnetic zenith during a time when the poleward edge of the aurora crossed the magnetic zenith (near 12:14 UT) and no NEIALs were observed. North is up and east is to the left. The PFISR field of view is marked by the white box near the center of the image.

\subsection{Auroral morphology context}

This case study using the limited aperture PFISR data provides evidence that these NEIALs occur with the same auroral morphology that is known to contain BBELF wave activity as measured in situ by satellites and sounding rockets (Bonnell et al., 1996; Kintner et al., 1996; Lynch et al., 1996, 2002; Knudsen and Wahlund, 1998; Wahlund et al., 1998) (as discussed in Sect. 2).

The NEIAL observations reported here occurred near magnetic midnight, and only one of the seven NEIALs was associated with rapid dynamic auroral rays. The other six were associated with structures that were part of a largescale arc stucture, and none of them were associated with "flaming" or "pumping" aurora, which is different than the observations reported by Blixt et al. (2005). All 7 of the NEIALs presented here are associated with thin filamentary dark auroral structures, (also different from previous obser-

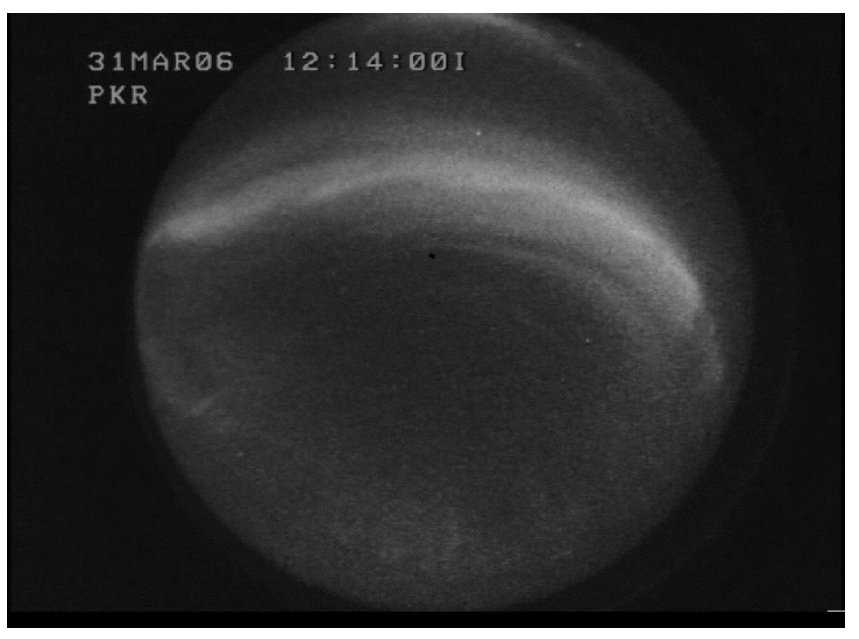

Fig. 11. An example all-sky camera image from 31 March 2006, showing the auroral context, and the poleward edge of the aurora near the magnetic zenith at the time of the image shown in Fig. 10. The black spot near the center marks the location of the radar beam. North is down and east is to the right.

vations) and these dark features could be associated with DCRs (Michell et al., 2008). The widths of these small dark features (few $\mathrm{km}$ ) are consistent with the widths of the smallest DCRs observed in situ (Hwang et al., 2006a,b). The counter-streaming dark and light auroral structures associated with these NEIAL observations are consistent with the diverging and converging electric field structures associated with auroral curls and with the small-scale upward and downward current sheets that are often observed in situ at the polar cap boundary. However, in Alfvénic aurora there may not be any clear distinction between the FAC direction and the electron precipitation (Goertz, 1984). Therefore the hypothesis that NEIALs occur in DCRs cannot be fully investigated with the current data set, and will be the focus of a future study, with the collection of more observations.

The structures visible in the magnetic zenith at the times of the enhancements, namely, fast auroral ray motion $(\sim 10 \mathrm{~km} / \mathrm{s}$ perpendicular to B) and thin dark auroral 


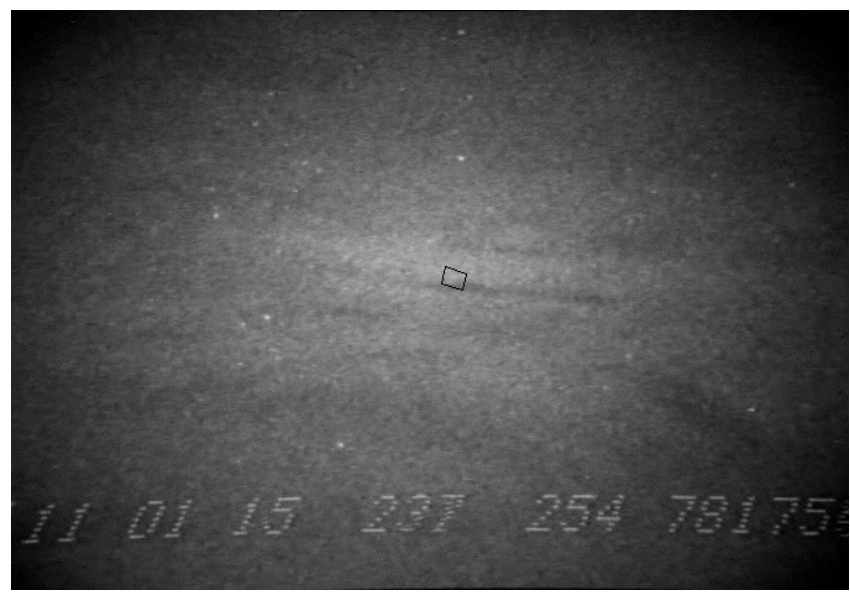

Fig. 12. The medium field camera image, from 18 January 2007, showing the black aurora patches in the magnetic zenith, which is indicated by the black box near the center of the image. North is up and east is to the left.

structures ( $\leq 1 \mathrm{~km}$ thickness perpendicular to $\mathrm{B}$ ), indicate that these regions may contain localized large electric fields and/or density gradients. These observations also corresponded to times when the polarcap boundary of the aurora was near magnetic zenith.

In order to test the hypothesis that the NEIAL occurrence required both conditions (poleward edge and thin dark auroral structures), times with only one condition must be investigated. Figure 3 shows that the poleward edge of the aurora comes close to the magnetic zenith at times other than the times when the NEIALs occurred. However, at these times, the narrow field camera did not show either fast auroral rays or thin dark structures. Figure 10 shows a narrow field image from the same night, near 12:14 UT (12.3 h on Fig. 3), when the poleward edge of the aurora passed through the magnetic zenith, but there were no small-scale dark auroral structures visible, and during this time no NEIALs were observed. The PFISR field of view is marked by the white box in Fig. 10 . Figure 11 shows the all-sky image corresponding to the time of the narrow field image in Fig. 10, with the PFISR field of view marked by the black spot near the center of the image. This shows the large-scale auroral context, illustrating the poleward edge of the aurora near the magnetic zenith.

Next is the examination of times with dark auroral structures in the radar field of view that are not associated with the polar cap boundary. Dark auroral structures were present when all 7 of these NEIALs were observed but their presence is not sufficient for NEIAL observation. On 18 January 2007, there was a good example of black aurora within diffuse aurora in the magnetic zenith, which lasted for several minutes. The radar data showed no signs of NEIAL activity throughout this whole period. Figure 12 is an example image from the medium field camera, illustrating these black aurora

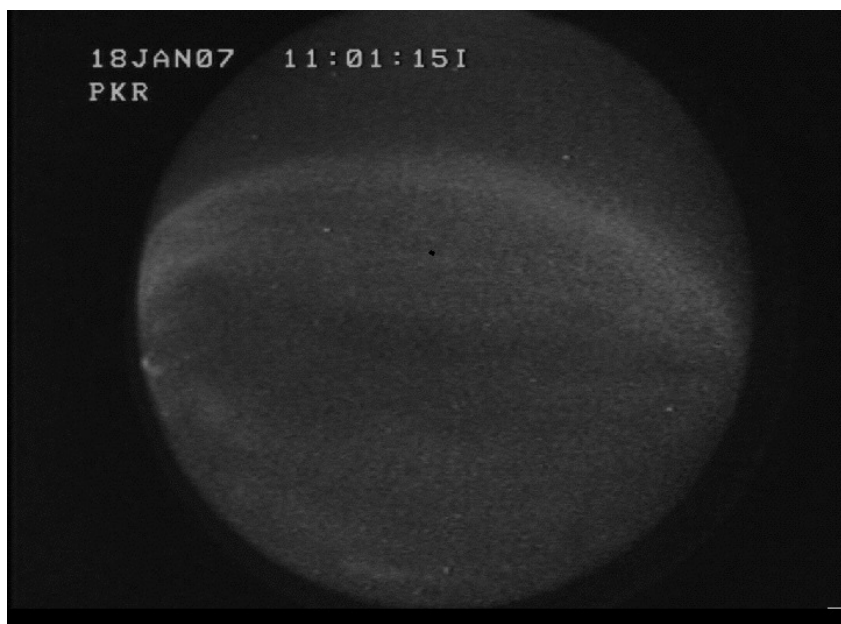

Fig. 13. The all-sky camera image, from 18 January 2007, showing the auroral context of the black aurora patches in the magnetic zenith (near the center of the image, marked by small black box). North is down and east is to the right.

patches. These structures were moving (from west to east) through the magnetic zenith for several minutes (the PFISR FOV in the magnetic zenith is indicated by the black box near the center of the image). Figure 13 shows the large-scale auroral context from the all-sky camera during this time. It can be seen that these black aurora patches were located inside a region of diffuse aurora, and were not at either the poleward or equatorward edge of the aurora. The PFISR field of view is marked by the black spot near the center of Fig. 13.

The data from this study show that NEIALs can occur in association with filamentary dark auroral structures. Further, our observations suggest that the thin dark structures could be auroral DCRs and the presence of NEIALs associated with these dark auroral features could be evidence of downward current or upgoing electron beams. The in situ studies of DCRs focused on quasi-static DCRs and they found scalesizes down to a few km (Hwang et al., 2006a).

The upward and downward currents associated with Alfvén waves, however, occur on even smaller scales and therefore cannot be approximated by sheet-like structures for the purpose of determining currents from magnetometer deflections. Therefore no good measure of their current densities can be made using the standard magnetometer analyses. With a more complete theoretical understanding of all the NEIAL generation mechanisms, and their relative importance under different auroral conditions, the presence and characteristics of NEIALs could provide a tool for estimating these very localized, large-amplitude current densities. 
Table 2. Summary of the observations of BBELF and their occurrence with transversely accelerated ions, downward current regions, polar cap boundary regions, and the cusp region.

\begin{tabular}{lcccccccc}
\hline Study & Alt. $(\mathrm{km})$ & $\log (\mathrm{Ne})\left(\mathrm{m}^{-3}\right)$ & $\mathrm{Ne}\left(\mathrm{cm}^{-3}\right)$ & Frequencies & TAI & DCR & PCB & cusp \\
\hline AMICIST & 850 & 9.0 & 1000 & $10 \mathrm{~Hz}-5 \mathrm{kHz}$ & yes & & yes & \\
SCIFER & 1400 & 8.7 & 500 & $20 \mathrm{~Hz}-5 \mathrm{kHz}$ & yes & & & yes \\
SIERRA & 735 & 10.3 & 22000 & $10-60 \mathrm{~Hz}$ & & & yes & \\
SERSIO & 782 & 10.7 & 60000 & $10 \mathrm{~Hz}-5 \mathrm{kHz}$ & $\sim$ & & & yes \\
FAST & $\sim 4000$ & 8.0 & $\sim 100$ & $0.1-10 \mathrm{kHz}$ & yes & yes & yes & yes \\
Cluster II & $\sim 28000$ & 6.0 & $\sim 1$ & $0.1-10 \mathrm{~Hz}$ & & & & \\
\hline
\end{tabular}

\subsection{Summary of BBELF}

The FAST satellite and numerous sounding rockets have allowed for a statistical picture of the morphological organization of the current structures within the auroral oval to be constructed. In particular, it was found that BBELF activity occurs in conjunction with DCRs containing up-going electron beams, density depletions, perpendicularly heated ions, and large fluxes of low energy $(\leq 1 \mathrm{keV})$ electrons.

The main characteristics of the auroral morphology associated with BBELF observations are summarized in Table 2. BBELF is found to contain at least a small magnetic component (Wahlund et al., 1998; Paschmann et al., 2003), indicating the presence of propagating, electromagnetic waves. This is consistent with the presence of Alfvén waves in the regions of BBELF activity. It has also been shown theoretically that breaking Alfvén waves could produce signatures consistent with BBELF observations (Seyler et al., 1998).

As described in Sect. 2, there have been many theoretical investigations done to understand BBELF (Kindel and Kennel, 1971; Seyler and Wu, 2001; Chaston et al., 2006; Kintner et al., 1996; Bonnell et al., 1996). Some BBELF observations can be explained by Doppler-shifted spatial irregularities, which refers to density or electric field structures with perpendicular phase velocities much less than the spacecraft velocity (usually a few $\mathrm{km} / \mathrm{s}$ ) and wavelengths on the order of tens of meters. These can account for BBELF up to a few hundred $\mathrm{Hz}$ (Paschmann et al., 2003). It is still unclear which features of BBELF are spatial and which are temporal. Most likely, BBELF is made up of a combination of ion-frequency wave phenomena together with Doppler broadening of spatial structures from irregular localized flows. The quantifiable experimental data for BBELF is limited, focusing on the (broad) frequency spectrum, with little available information on the k-vectors. This makes it unclear as to which theories best describe the observed phenomena.

\subsection{Implications for theories of NEIALs}

In ordinary incoherent scatter theory, the macroscopic plasma parameters define the dispersion relation $\frac{\omega}{k}=V_{i a}$, the ion-acoustic (sound) speed. A given radar operates at a par- ticular k-vector, therefore selecting a frequency offset. In the PFISR data, the ion-acoustic shoulders occur at a frequency offset of $\sim 6 \mathrm{kHz}$. PFISR, operating at a frequency of $449.3 \mathrm{MHz}$, has a wavelength of $\lambda=0.66 \mathrm{~m}$. Pointed up the magnetic field, PFISR selects waves along $\mathrm{B}$ with the single k-vector of the radar half-wavelength, $\frac{\lambda}{2}=0.33 \mathrm{~m}$. Using this $\mathrm{k}$-vector, the ion-acoustic speed is estimated to be $V_{i a} \approx 2 \mathrm{~km} / \mathrm{s}$. The electron temperature can be estimated from the definition of the ion-acoustic speed, $V_{i a}=\sqrt{\frac{\gamma Z k T_{e}}{m_{i}}}$, where $\gamma$ is the adiabatic index, $Z$ is the charge state, and $k$ is Boltzmann's constant. With the assumption that the main ion species is $\mathrm{O}^{+}$, the electron temperature $\left(T_{e}\right)$ was found to be approximately $0.25 \mathrm{eV}$ for this event.

NEIAL returns are not the same as incoherent scatter, however their occurrence at the ion-acoustic frequency in the radar data indicates that the scattering is from ion-acoustic wave activity. Assuming that the NEIAL returns are originating within a region of enhanced wave activity, it is believed that they are coming from only a small fraction of the wave activity present in the plasma, since the radar selects only one wave number $(0.33 \mathrm{~m})$ and one direction (field-aligned).

The wave properties of NEIALs can be summarized with the statement that the strongest returns occur at a frequency offset corresponding to the local ion-acoustic speed given the radar k-vector. Therefore different radars operating at different frequencies will observe different frequency offsets for the NEIALs, but they all are interpreted as the ion-acoustic speed.

Next we compare the few reported measurements of phase velocities $\left(\frac{\omega}{k}\right)$ for BBELF from sounding rockets within the same altitude range observed by the radars $(500-1000 \mathrm{~km})$. Bonnell et al. (1996) (AMICIST) measured the phase velocity of BBELF both parallel and perpendicular to the magnetic field, and found that $V_{\perp} \approx 10 \mathrm{~km} / \mathrm{s}$, and $V_{\|} \approx 30-50 \mathrm{~km} / \mathrm{s}$, implying a $k_{\perp} \sim 2 \mathrm{~m}^{-1}$ and $k_{\|} \sim 6-10 \mathrm{~m}^{-1}$ at $5 \mathrm{kHz}$. Klatt et al. (2005) (SIERRA) reported another measurement of the perpendicular phase velocity and found $V_{\perp} \approx 1.8 \mathrm{~km} / \mathrm{s}$. Another measurement of BBELF where a perpendicular phase velocity can be estimated was reported in Frederick-Frost et al. (2007) (SERSIO), and in this case $V_{\perp} \approx 1 \mathrm{~km} / \mathrm{s}$, again implying $k_{\perp} \sim 1 \mathrm{~m}^{-1}$ at $5 \mathrm{kHz}$. The values for these phase 
Table 3. Summary of the phase velocity measurements of BBELF.

\begin{tabular}{lcc}
\hline Rocket & $\frac{\omega}{k_{\perp}}$ & $\frac{\omega}{k_{\|}}$ \\
\hline AMICIST & $\sim 10 \mathrm{~km} / \mathrm{s}$ & $\sim 30-50 \mathrm{~km} / \mathrm{s}$ \\
SIERRA & $\sim 1.8 \mathrm{~km} / \mathrm{s}$ & NA \\
SERSIO & $\sim 1.0 \mathrm{~km} / \mathrm{s}$ & NA \\
\hline
\end{tabular}

velocities are summarized in Table 3 . There is an order of magnitude difference among these perpendicular velocities, which indicates that BBELF measurements are not fully understood and that there may be many different wave modes involved. Recent observations by Chaston et al. (2006) report a mechanism for a feedback model of Alfvén wave focusing on density gradients. This mechanism leads to ion heating, and the generation of waves with k-spectra consistent with the available BBELF measurements. For example, a k-vector of $3.0 \mathrm{~m}^{-1}$ (consistent with the PFISR halfwavelength) produces a signal at $3000 \mathrm{~Hz}$. This is within a factor of 2 from the actual measurements, indicating that such processes could be responsible for generating BBELF wave activity that would lead to NEIALs.

The phase velocities associated with the NEIALs $(\sim$ few $\mathrm{km} / \mathrm{s}$ ) are assumed to be associated with that of the ionacoustic dispersion surface. This is comparable to the measured values for the phase velocities of BBELF (1 to $1.8 \mathrm{~km} / \mathrm{s}$ ) (Klatt et al., 2005; Frederick-Frost et al., 2007). However these BBELF measurements were both perpendicular to the magnetic field, while NEIALs are predominately observed parallel to the magnetic field. The ion-acoustic surface however, contains allowed modes at oblique angles to the magnetic field, but radars typically observe NEIALs within $\sim 15^{\circ}$ of the parallel direction (Rietveld et al., 1991), and they have been observed up to about $30^{\circ}$ away (Foster et al., 1988; Rietveld et al., 1996). One example might be that shown by Stringer (1963), with the two-fluid dispersion relation for ion acoustic waves in a low-beta plasma (similar to the ionosphere). Stringer (1963) showed that the waves tend to have nearly field aligned group velocities, corroborating the field-aligned nature of NEIAL observations. The one parallel measurement of phase velocity for BBELF (Bonnell et al., 1996) is considerably higher $(30-50 \mathrm{~km} / \mathrm{s})$ than the few $\mathrm{km} / \mathrm{s}$ associated with the NEIALs. Bonnell et al. (1996) also measured a higher value for the perpendicular phase velocity $(\sim 10 \mathrm{~km} / \mathrm{s})$ than the values reported in Klatt et al. (2005) and Frederick-Frost et al. (2007). The rocket measurements of BBELF are at different wave numbers than those associated with the radar observations of NEIALs. However, it is possible that the parallel phase velocities associated with BBELF wave activity do contain values in the same range as those associated with the NEIALs. Another interpretation of NEIALs is that they are coherent backscatter from density irregularities traveling along the field-aligned direction, which would explain why they are preferentially observed along that direction. These would have to travel at the ion-acoustic speed for the Doppler shift of the returns to be consistent with NEIAL observations. This interpretation cannot be negated for these NEIAL observations. It is possible to have irregularities traveling both directions along the magnetic field during the NEIAL events, given the $10 \mathrm{~s}$ integrations. Therefore scattering from traveling density irregularities still remains one of the possible generation mechanisms to explain these data. This picture would be consistent with BBELF as Doppler shifted spatial structures.

These observations support the hypothesis that NEIALs are occurring in auroral morphology associated with DCRs, either Alfvénic or quasi-static. One possible explanation for this association is that the decreased density, and therefore conductivity, inside DCRs causes the creation of the ionospheric Alfvén resonator (Streltsov and Lotko, 2005, 2004; Streltsov and Mishin, 2003; Streltsov and Lotko, 2003). This allows for the creation of intense Alfvén waves, and the relatively high frequency $(0.1$ to $1 \mathrm{~Hz})$ ones can then cause localized density cavities through the action of the ponderomotive force (Chaston et al., 2003, 2006), which has been shown to initiate ion upflows ( $\mathrm{Li}$ and Temerin, 1993). This is consistent with observations, as NEIAL activity has been found to be associated with enhanced ion upflow (Ogawa et al., 2000). The individual regions of NEIAL activity have been shown to be small (few hundred meters) in the direction perpendicular to the magnetic field (Grydeland et al., 2003, 2004), therefore the theories only need to show that ion-acoustic waves can be driven unstable in very localized regions. This makes it difficult to associate NEIAL occurrence with intense ion upflows, as the upflows would be taking place in only a small percentage of the radar beam volume and for only a short time, therefore becoming averaged out. However, regions with significant NEIAL activity would show some increase in the bulk upflow velocity of the plasma, as was observed by Ogawa et al. (2000).

The three prevalent theories of NEIAL generation in the literature presume differing auroral morphology, and all three assume that energy flows from the particles to the waves. An alternate interpretation is that the energy is going from the waves to the particles, for example, the driving energy coming from Alfvén waves through the Alfvén resonator modes (Streltsov and Lotko, 2005, 2004; Streltsov and Mishin, 2003; Streltsov and Lotko, 2003).

For PFISR to observe NEIALs, the Bragg condition for the field-aligned PFISR beam would consist of having BBELF waves with $k_{\|}=0.33 \mathrm{~m}$. Using only these ground-based morphological arguments, it cannot be ruled out that NEIALs could be a different phenomenon that happen to occur on the same flux tubes as BBELF, with the same types of auroral morphology and many overlapping parameters. The present measurements of both BBELF and NEIALs are fairly limited and a better understanding of the processes causing both NEIALs and BBELF is needed to address this question. 
A truly common-volume in situ and radar study is needed to prove that NEIALs and BBELF occur together. However the complement of ground-based and in situ data available to date do show that NEIALs and BBELF occur with the same types of auroral morphology. Radar observations of NEIALs can provide wavenumber information about the waves in the scattering region, while in situ measurements typically can only measure frequencies. A combination of the two methods, therefore, will provide much more information about the wave activity than either method alone.

\section{Conclusions}

The data presented here are the first PFISR observations of naturally enhanced ion lines, and these data are complemented by common-volume high-resolution television images of the aurora. These NEIALs occur on or very near the poleward edge of the aurora, and inside or just poleward of the most intense $630.0 \mathrm{~nm}$ auroral emissions. It is seen that during the times of the NEIALs there is soft electron precipitation, as evidenced by the extended altitude range of the auroral E-region enhancement, as well as the enhanced $630.0 \mathrm{~nm}$ emissions during those times. During the NEIAL events the narrow field camera data show dynamic small-scale dark auroral structures, which provides evidence for the NEIALs occurring in small-scale DCRs associated with these dark auroral structures. The occurrence of these NEIALs is associated with the existence of soft electron precipitation and dark auroral structures, consistent with the in situ signatures of polar cap boundary aurora. The review of previous observations indicate that there may be a density dependence for NEIAL occurrence. NEIALs have been found to occur within a range of densities ( 5 to $30 \times 10^{10} \mathrm{~m}^{-3}$ ).

These observations, together with recent in situ observations of DCRs, Alfvénic, and polar cap boundary aurora from Cluster, FAST, and sounding rockets indicate a connection, through morphology, between NEIALs and BBELF. PFISR observed these NEIALs associated with the poleward boundary of the auroral arc, dynamic auroral rays, small-scale dark auroral structures, and enhanced $630.0 \mathrm{~nm}$ auroral emissions.

The data presented here motivate the need for more observations, because establishing definitive links between what is seen in ground-based instrumentation such as cameras, MSPs, and radars, and specific in situ processes, specifically downward current regions and ion outflows, allows for the use of ground-based data as a large-scale proxy for important in situ processes that cannot be measured directly over large areas and times. This could be a valuable use of large-scale ground-based arrays of instruments, such as the THEMIS array of all-sky cameras recently constructed in Canada and Alaska.
Acknowledgements. This work was supported under NASA grant \# NAG5-5415 and the NASA space grant \# NNG05GG76H. The authors thank Kyoung-Joo Hwang for providing the FAST data figures, Marc Lessard for the use of the medium field camera, and G. T. Marklund, T. Karlsson, N. Ivchenko, J. Semeter, W. Lotko, and R. Millan for their valuable input. Meridian scanning photometer data were provided by the Geophysical Institute, University of Alaska.

Topical Editor M. Pinnock thanks two anonymous referees for their help in evaluating this paper.

\section{References}

André, M., Norqvist, P., Andersson, L., Eliasson, L., Eriksson, A. I., Blomberg, L., Erlandson, R. E., and Waldemark, J.: Ion energization mechanisms at $1700 \mathrm{~km}$ in the auroral region, J. Geophys. Res., 103, 4199-4222, 1998.

Arnoldy, R. L., Lynch, K. A., Austin, J. B., and Kintner, P. M.: Energy and Pitch-Angle Dispersed Auroral Electrons Suggesting a Time-Variable, Inverted-V Potential Structure, J. Geophys. Res., 104, 22 613-22 622, 1999.

Blixt, E. M., Grydeland, T., Ivchenko, N., Hagfors, T., La Hoz, C., Lanchester, B. S., Løvhaug, U. P., and Trondsen, T. S.: Dynamic rayed aurora and enhanced ion-acoustic radar echoes, Ann. Geophys., 23, 3-11, 2005, http://www.ann-geophys.net/23/3/2005/.

Bonnell, J., Kintner, P., Wahlund, J. E., Lynch, K., and Arnoldy, R.: Interferometric determination of broadband ELF wave phase velocity within a region of transverse auroral ion acceleration, Geophys. Res. Lett., 23, 3297-3300, 1996.

Carlson, C. W., McFadden, J. P., Ergun, R. E., Temerin, M., Peria, W., Mozer, F. S., Klumpar, D. M., Shelley, E. G., Peterson, W. K., Moebius, E., Elphic, R., Strangeway, R., Cattell, C., and Pfaff, R. F.: FAST observations in the downward auroral current region: Energetic upgoing electron beams, parallel potential drops, and ion heating, Geophys. Res. Lett., 25, 2017-2020, 1998.

Chaston, C. C., Carlson, C. W., Peria, W. J., Ergun, R. E., and McFadden, J. P.: FAST observations of inertial Alfven waves in the dayside aurora, Geophys. Res. Lett., 26, 647-650, 1999.

Chaston, C. C., Peticolas, L. M., Bonnell, J. W., Carlson, C. W., Ergun, R. E., McFadden, J. P., and Strangeway, R. J.: Width and brightness of auroral arcs driven by inertial Alfven waves, J. Geophys. Res., 108(A2), 1091, doi:10.1029/2001JA007537, 2003.

Chaston, C. C., Genot, V., Bonnell, J. W., Carlson, C. W., McFadden, J. P., Ergun, R. E., Strangeway, R. J., Lund, E. J., and Hwang, K. J.: Ionospheric erosion by Alfvén waves, J. Geophys. Res., 111(A10), 3206, doi:10.1029/2005JA011367, 2006.

Collis, P. N., Haggstrom, I., Kaila, K., and Rietveld, M. T.: EISCAT radar observations of enhanced incoherent scatter spectra and their relation to red aurora and field-aligned currents, Geophys. Res. Lett., 18, 1031-1034, 1991.

Forme, F. R. E.: A new interpretation of the origin of enhanced ion acoustic fluctuations in the upper ionosphere, Geophys. Res. Lett., 20, 2347-2350, 1993.

Forme, F. R. E.: Parametric decay of beam-driven Langmuir wave and enhanced ion-acoustic fluctuations in the ionosphere: a weak 
turbulence approach, Ann. Geophys., 17, 1172-1181, 1999, http://www.ann-geophys.net/17/1172/1999/.

Forme, F. R. E. and Fontaine, D.: Enhanced ion acoustic fluctuations and ion outflows, Ann. Geophys., 17, 182-189, 1999, http://www.ann-geophys.net/17/182/1999/.

Foster, J. C., del Pozo, C., Groves, K., and Saint Maurice, J.-P.: Radar observations of the onset of current driven instabilities in the topside ionosphere, Geophys. Res. Lett., 15, 160-163, 1988.

Frederick-Frost, K. M., Lynch, K. A., Kintner, P., Klatt, E., Ogawa, Y., Lorentzen, D., Moen, J., and Widholm, M.: SERSIO: Svalbard EISCAT rocket study of ion outflows, J. Geophys. Res., 112(A11), 8307, doi:10.1029/2006JA011942, 2007.

Goertz, C. K.: Kinetic Alfvén waves on auroral field lines, Planet. Space Sci., 32, 1387-1392, 1984.

Groves, K. M.: Nonlinear Ionospheric Propagation Effects on UHF and VLF Radio Signals., Ph.D. thesis, Massachusetts Institute of Technology, 1991.

Grydeland, T., La Hoz, C., Hagfors, T., Blixt, E. M., Saito, S., Strømme, A., and Brekke, A.: Interferometric observations of filamentary structures associated with plasma instability in the auroral ionosphere, Geophys. Res. Lett., 30(6), 1338, doi:10.1029/2002GL016362, 2003.

Grydeland, T., Blixt, E., Løvhaug, U., Hagfors, T., La Hoz, C., and Trondsen, T.: Interferometric radar observations of filamented structures due to plasma instabilities and their relation to dynamic auroral rays, Ann. Geophys., 22, 1115-1132, 2004, http://www.ann-geophys.net/22/1115/2004/.

Hallinan, T. J., Kimball, J., Stenbaek-Nielsen, H. C., Lynch, K., Arnoldy, R., Bonnell, J., and Kintner, P.: Relation between optical emissions, particles, electric fields, and Alfvén waves in a multiple rayed arc, J. Geophys. Res., 106, 15 445-15 454, 2001.

Hwang, K.-J., Lynch, K. A., Carlson, C. W., Bonnell, J. W., and Peria, W. J.: Fast Auroral Snapshot observations of perpendicular DC electric field structures in downward auroral current regions: Morphology, J. Geophys. Res., 111, 9205, doi:10.1029/2005JA011472, 2006a.

Hwang, K.-J., Lynch, K. A., Carlson, C. W., Bonnell, J. W., and Peria, W. J.: Fast Auroral Snapshot observations of perpendicular DC electric field structures in downward current regions: Implications, J. Geophys. Res., 111, 9206, doi:10.1029/2005JA011471, 2006b.

Ivchenko, N., Blixt, E. M., and Lanchester, B. S.: Multispectral observations of auroral rays and curls, Geophys. Res. Lett., 32, 18 106, doi:10.1029/2005GL022650, 2005.

Kelly, J. D., Heinselman, C. J., and Valentic, T.: A new instrument for ionospheric research-AMISR, AGU Fall Meeting Abstracts, 2006.

Kindel, J. M. and Kennel, C. F.: Topside current instabilities, J. Geophys. Res., 76, 3055-3078, 1971.

Kintner, P. M., Bonnell, J., Arnoldy, R., Lynch, K., Pollock, C., and Moore, T.: SCIFER-Transverse ion acceleration and plasma waves, Geophys. Res. Lett., 23, 1873-1876, 1996.

Klatt, E. M., Kintner, P. M., Seyler, C. E., Liu, K., MacDonald, E. A., and Lynch, K. A.: SIERRA observations of Alfvénic processes in the topside auroral ionosphere, J. Geophys. Res., 110, A10512, doi:10.1029/2004JA010883, 2005.

Knudsen, D. J. and Wahlund, J.-E.: Core ion flux bursts within solitary kinetic Alfvén waves, J. Geophys. Res., 103, 4157-4170, 1998.
Li, X. and Temerin, M.: Ponderomotive effects on ion acceleration in the auroral zone, Geophys. Res. Lett., 20, 13-16, 1993.

Louarn, P., Wahlund, J. E., Chust, T., de Feraudy, H., Roux, A., Holback, B., Dovner, P. O., Eriksson, A. I., and Holmgren, G.: Observation of kinetic Alfven waves by the Freja spacecraft, Geophys. Res. Lett., 21, 1847-1850, 1994.

Lunde, J., Gustavsson, B., Løvhaug, U. P., Lorentzen, D. A., and Ogawa, Y.: Particle precipitations during NEIAL events: simultaneous ground based observations at Svalbard, Ann. Geophys., 25, 1323-1336, 2007, http://www.ann-geophys.net/25/1323/2007/.

Lynch, K. A., Arnoldy, R. L., Kintner, P. M., and Bonnell, J.: The AMICIST auroral sounding rocket: A comparison of transverse ion acceleration mechanisms, Geophys. Res. Lett., 23, 32933296, 1996.

Lynch, K. A., Bonnell, J. W., Carlson, C. W., and Peria, W. J.: Return current region aurora: $E_{\text {parallel }}, j_{z}$, particle energization, and broadband ELF wave activity, J. Geophys. Res., 107(A7), 1115, doi:10.1029/2001JA900134, 2002.

Lynch, K. A., Semeter, J. L., Zettergren, M., Kintner, P., Arnoldy, R., Klatt, E., LaBelle, J., MacDonald, E. A., Michell, R. G., and Samara, M.: Auroral ion outflow: low altitude energization, Ann. Geophys., 25, 1967-1977, 2007, http://www.ann-geophys.net/25/1967/2007/.

McFadden, J. P., Carlson, C. W., Ergun, R. E., Mozer, F. S., Temerin, M., Peria, W., Klumpar, D. M., Shelley, E. G., Peterson, W. K., Moebius, E., Kistler, L., Elphic, R., Strangeway, R., Cattell, C., and Pfaff, R.: Spatial structure and gradients of ion beams observed by FAST, Geophys. Res. Lett., 25, 2021-2024, 1998.

Michell, R. G., Lynch, K. A., Heinselsan, C. J., and StenbaekNielsen, H. C.: High time-resolution AMISR and optical observations of naturally enhanced ion-acoustic lines, Ann. Geophys., in review, 2008.

Michell, R. G., Lynch, K. A., and Stenbaek-Nielsen, H. C.: Groundbased observational signature of a downward current channel in an active auroral arc, Geophys. Res. Lett., 35, L08101, doi:10.1029/2008GL033569, 2008.

Neubert, T. and Christiansen, F.: Small-scale, field-aligned currents at the top-side ionosphere, Geophys. Res. Lett., 30(19), 2010, doi:10.1029/2003GL017808, 2003.

Norqvist, P., André, M., and Tyrland, M.: A statistical study of ion energization mechanisms in the auroral region, J. Geophys. Res., 103, 23 459-23 474, 1998.

Ogawa, Y., Fujii, R., Buchert, S. C., Nozawa, S., Watanabe, S., and van Eyken, A. P.: Simultaneous EISCAT Svalbard and VHF radar observations of ion upflows at different aspect angles, Geophys. Res. Lett., 27, 81-84, 2000.

Ogawa, Y., Buchert, S. C., Fujii, R., Nozawa, S., and Forme, F.: Naturally enhanced ion-acoustic lines at high altitudes, Ann. Geophys., 24, 3351-3364, 2006, http://www.ann-geophys.net/24/3351/2006/.

Paschmann, G., Haaland, S., and Treumann, R.: Auroral Plasma Physics, Kluwer Academic Publishers, The Netherlands, 2003.

Rietveld, M. T., Collis, P. N., and St.-Maurice, J.-P.: Naturally enhanced ion acoustic waves in the auroral ionosphere observed with the EISCAT 933-MHz radar, J. Geophys. Res., 96, 1929119305, 1991.

Rietveld, M. T., Collis, P. N., Vaneyken, A. P., and L_vhaug, U. P.: 
Coherent echoes during EISCAT UHF Common Programmes, J. Atmos. Terr. Phys., 58, 161-174, 1996.

Rosenbluth, M. N. and Rostoker, N.: Scattering of Electromagnetic Waves by a Nonequilibrium Plasma, Phys. Fluids, 5, 776-788, 1962.

Sedgemore-Schulthess, K. J. F., Lockwood, M., Trondsen, T. S., Lanchester, B. S., Rees, M. H., Lorentzen, D. A., and Moen, J.: Coherent EISCAT Svalbard Radar spectra from the dayside cusp/cleft and their implications for transient field-aligned currents, J. Geophys. Res., 104, 24 613-24 624, 1999.

Seyler, C. E. and Wu, K.: Instability at the electron inertial scale, J. Geophys. Res., 106, 21 623-21 644, 2001.

Seyler, C. E., Clark, A. E., Bonnell, J., and Wahlund, J.-E.: Electrostatic broadband ELF wave emission by Alfvén wave breaking, J. Geophys. Res., 103, 7027-7042, 1998.

St.-Maurice, J.-P., Kofman, W., and James, D.: In situ generation of intense parallel electric fields in the lower ionosphere, J. Geophys. Res., 101, 335-356, doi:10.1029/95JA02586, 1996.

St.-Maurice, J.-P., Cussenot, C., and Kofman, W.: On the usefulness of $\mathrm{E}$ region electron temperatures and lower $\mathrm{F}$ region ion temperatures for the extraction of thermospheric parameters: a case study, Ann. Geophys., 17, 1182-1198, 1999, http://www.ann-geophys.net/17/1182/1999/.

Strangeway, R. J., Ergun, R. E., Su, Y.-J., Carlson, C. W., and Elphic, R. C.: Factors controlling ionospheric outflows as observed at intermediate altitudes, J. Geophys. Res., 110, 3221, doi:10.1029/2004JA010829, 2005.

Streltsov, A. V. and Lotko, W.: Small-scale electric fields in downward auroral current channels, J. Geophys. Res., 108, 13-1, doi: 10.1029/2002JA009806, 2003.

Streltsov, A. V. and Lotko, W.: Multiscale electrodynamics of the ionosphere-magnetosphere system, J. Geophys. Res., 109, 9214, doi:10.1029/2004JA010457, 2004.
Streltsov, A. V. and Lotko, W.: Ultra-low-frequency electrodynamics of the magnetosphere-ionosphere interaction, J. Geophys. Res., 110, 8203, doi:10.1029/2004JA010764, 2005.

Streltsov, A. V. and Mishin, E. V.: Numerical modeling of localized electromagnetic waves in the nightside subauroral zone, J. Geophys. Res., 108, 13-1, doi:10.1029/2003JA009858, 2003.

Stringer, T. E.: Low-frequency waves in an unbounded plasma , J. Nucl. Energy, 5, 89-107, 1963.

Strømme, A., Belyey, V., Grydeland, T., La Hoz, C., Løvhaug, U. P., and Isham, B.: Evidence of naturally occurring wavewave interactions in the polar ionosphere and its relation to naturally enhanced ion acoustic lines, Geophys. Res. Lett., 32, 5103, doi:10.2029/2004GL020239, 2005.

Trondsen, T. S. and Cogger, L. L.: High-resolution television observations of black aurora, J. Geophys. Res., 102, 363-378, 1997.

Wahlund, J.-E., Eriksson, A. I., Holback, B., Boehm, M. H., Bonnell, J., Kintner, P. M., Seyler, C. E., Clemmons, J. H., Eliasson, L., Knudsen, D. J., Norqvist, P., and Zanetti, L. J.: Broadband ELF plasma emission during auroral energization 1. Slow ion acoustic waves, J. Geophys. Res., 103, 4343-4376, 1998.

Wygant, J. R., Keiling, A., Cattell, C. A., Johnson, M., Lysak, R. L., Temerin, M., Mozer, F. S., Kletzing, C. A., Scudder, J. D., Peterson, W., Russell, C. T., Parks, G., Brittnacher, M., Germany, G., and Spann, J.: Polar spacecraft based comparisons of intense electric fields and Poynting flux near and within the plasma sheet-tail lobe boundary to UVI images: An energy source for the aurora, J. Geophys. Res., 105, 18 675-18 692, 2000.

Zheng, Y., Moore, T. E., Mozer, F. S., Russell, C. T., and Strangeway, R. J.: Polar study of ionospheric ion outflow versus energy input, J. Geophys. Res., 110, 7210, doi:10.1029/2004JA010995, 2005. 